\title{
Comparison of CFD predictions with shuttle global flight thermal imagery and discrete surface measurements
}

\author{
William A. Wood* and William L. Kleb* \\ NASA Langley Research Center, Hampton, Virginia, 23681 \\ Chun Y. Tang ${ }^{\dagger}$ \\ NASA Ames Research Center, Moffett Field, California, 94035 \\ Grant E. Palmer ${ }^{\ddagger}$ and Andrew J. Hyatt ${ }^{\S}$ \\ ELORET Corporation, Sunnyvale, California, 94086 \\ Adam J. Wise \\ Analytical Mechanics Associates, Inc., Hampton, Virginia, 23666 \\ Peter L. McCloud" \\ The Boeing Company, Houston, Texas, 77059
}

\begin{abstract}
Surface temperature measurements from the STS-119 boundary-layer transition experiment on the space shuttle orbiter Discovery provide a rare opportunity to assess turbulent CFD models at hypersonic flight conditions. This flight data was acquired by on-board thermocouples and by infrared images taken off-board by the Hypersonic Thermodynamic Infrared Measurements (HYTHIRM) team, and is suitable for hypersonic CFD turbulence assessment between Mach 6 and 14. The primary assessment is for the Baldwin-Lomax and Cebeci-Smith algebraic turbulence models in the DPLR and LAURA CFD codes, respectively. A secondary assessment is made of the Shear-Stress Transport (SST) two-equation turbulence model in the DPLR code. Based upon surface temperature comparisons at eleven thermocouple locations, the algebraic-model turbulent CFD results average $4 \%$ lower than the measurements for Mach numbers less than 11. For Mach numbers greater than 11, the algebraic-model turbulent CFD results average 5\% higher than the three available thermocouple measurements. Surface temperature predictions from the two SST cases were consistently 3-4\% higher than the algebraic-model results. The thermocouple temperatures exhibit a change in trend with Mach number at about Mach 11; this trend is not reflected in the CFD results. Because the temperature trends from the turbulent CFD simulations and the flight data diverge above Mach 11, extrapolation of the turbulent CFD accuracy to higher Mach numbers is not recommended.
\end{abstract}

\section{Nomenclature}

Symbols

$h \quad$ Altitude, $\mathrm{km}$

$M \quad$ Mach number

*Aerothermodynamics Branch, senior lifetime AIAA member.

$\dagger$ Aerothermodynamics Branch, AIAA member.

¥Senior Research Scientist, AIAA Associate Fellow.

$\S$ Research Scientist, AIAA member.

IProject Engineer.

\| Entry Aeroheating Engineer, Space Exploration M/C HB2-30, AIAA member. 


$\begin{array}{ll}T & \text { Temperature, non-dimensionalized } \\ X / L & \text { Axial position as fraction of vehicle length, percent } \\ Y / L & \text { Span-wise position as fraction of vehicle length, percent } \\ \alpha & \text { Angle of attack, degrees } \\ \beta & \text { Sideslip angle, degrees }\end{array}$

\section{Acronyms}

$\begin{array}{ll}\text { CFD } & \text { Computational fluid dynamics } \\ \text { DPLR } & \text { Data-parallel line relaxation CFD code } \\ \text { HYTHIRM } & \text { Hypersonic thermodynamic infrared measurements } \\ \text { LAURA } & \text { Langley aerothermodynamic upwind relaxation algorithm CFD code } \\ \text { OML } & \text { Outer mold line } \\ \text { RCC } & \text { Reinforced carbon-carbon } \\ \text { RCG } & \text { Reaction-cured glass } \\ \text { SST } & \text { Shear-stress transport } \\ \text { STS } & \text { Space transportation system } \\ \text { TC } & \text { Thermocouple }\end{array}$

\section{Introduction}

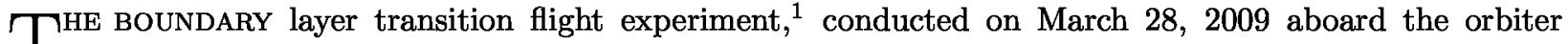
1 Discovery during the STS-119 space shuttle mission, provides a rare opportunity to assess turbulent CFD models against hypersonic flight data. The best set of turbulent hypersonic flow measurements from the prior 124 space shuttle missions was from STS-28, when the orbiter experienced turbulent flow at approximately Mach 16 during reentry. The data acquired from the STS-28 entry consists of windward surface temperatures from two thermocouples, one of which has an apparent large bias error, and is not sufficient for CFD validation purposes.

The STS-119 flight experiment had a windward-side boundary layer trip—a specially-constructed thermal protection tile with a single protuberance approximately four inches long by a quarter-inch tall-mounted on the orbiter's port wing. Sixteen thermocouples, installed under the RCG coatings of various windward side tiles, recorded temperature time histories throughout the entry. Nine of these thermocouples were clustered in the vicinity of the boundary layer trip. As inferred from jumps in the surface temperature measurements, the trip caused boundary layer transition at approximately Mach 15.5 during the vehicle's reentry into the atmosphere en route toward landing. Turbulent, as opposed to transitional, flow was evident from about Mach 13 and below. The data from eleven of the sixteen thermocouples were used in the present report to assess turbulent CFD predictive capability.

In addition to the on-board thermocouple measurements, the Hypersonic Thermodynamic Infrared Measurements (HYTHIRM) team collected off-board measurements of the orbiter surface temperatures using an infrared video system operated from a Department of Defense aerial asset. HYTHIRM details were presented in a series of reports at the $48^{\text {th }}$ AIAA Aerospace Sciences Meeting: a general project overview; ${ }^{2}$ a review of the mission planning and execution from the perspective of the flight crew ${ }^{3}$ a description of the digital near-infrared imaging system and its calibration $;^{4}$ and a description of the pre-flight simulated orbiter infrared signature that was used to configure the imaging system and to optimize the instrumentation's settings along with the post-flight data reduction process. ${ }^{5}$ The best HYTHIRM data for CFD comparison, with the highest spatial resolution and lowest uncertainties, corresponds to Mach 8.4.

The present report seeks to assess the accuracy and precision of turbulent CFD models for the prediction of radiative-equilibrium surface temperatures on the windward acreage of the space shuttle orbiter at hypersonic reentry conditions. The results should be applicable to winged or lifting-body entry vehicles, and may provide guidance for general hypersonic turbulent CFD applications.

A contemporary report by Candler ${ }^{6}$ performs a similar assessment to the present work. Specific differences in Candler's report are the CFD code, US3D, the turbulence model, Spallart-Allmaras, and the use of an unstructured grid. Further, Candler presents mixed laminar/turbulent CFD simulations using a novel pointsource boundary layer tripping mechanism, as opposed to the fully-turbulent or fully-laminar results included herein. 


\begin{tabular}{lcl} 
Full name & Short name & Note \\
\hline V07T9751A & TC-51 & Downstream of trip. \\
V07T9752A & TC-52 & Downstream of trip. \\
V07T9753A & TC-53 & Downstream of trip. \\
V07T9754A & TC-54 & Downstream of trip. \\
V07T9756A & TC-56 & Downstream of trip. \\
V07T9757A & TC-57 & Downstream of trip. \\
V07T9758A & TC-58 & Downstream of trip. \\
V07T9468A & TC-68 & Forward centerline. \\
V07T9480A & TC-80 & Port mid-fuselage. \\
V07T9590A & TC-90 & Aft centerline. \\
V07T9597A & TC-97 & Starboard mid-fuselage. \\
\hline V07T9711A & TC-11 & Port wing tip. \\
V07T9929A & TC-29 & On boundary layer trip. \\
V07T9730A & TC-30 & On elevon. \\
V07T9755A & TC-55 & Close to trip. \\
V07T9666A & TC-66 & Near RCC/RCG interface.
\end{tabular}

Table 1. Thermocouple names and locations. The bottom group was not used for the present accuracy assessment.

To allow for unrestricted distribution of the present results, the data is non-dimensional. Specifically, temperatures are reported as non-dimensional absolute temperatures, so that percentage differences may be compared, but the non-dimensionalizing factor is intentionally not reported.

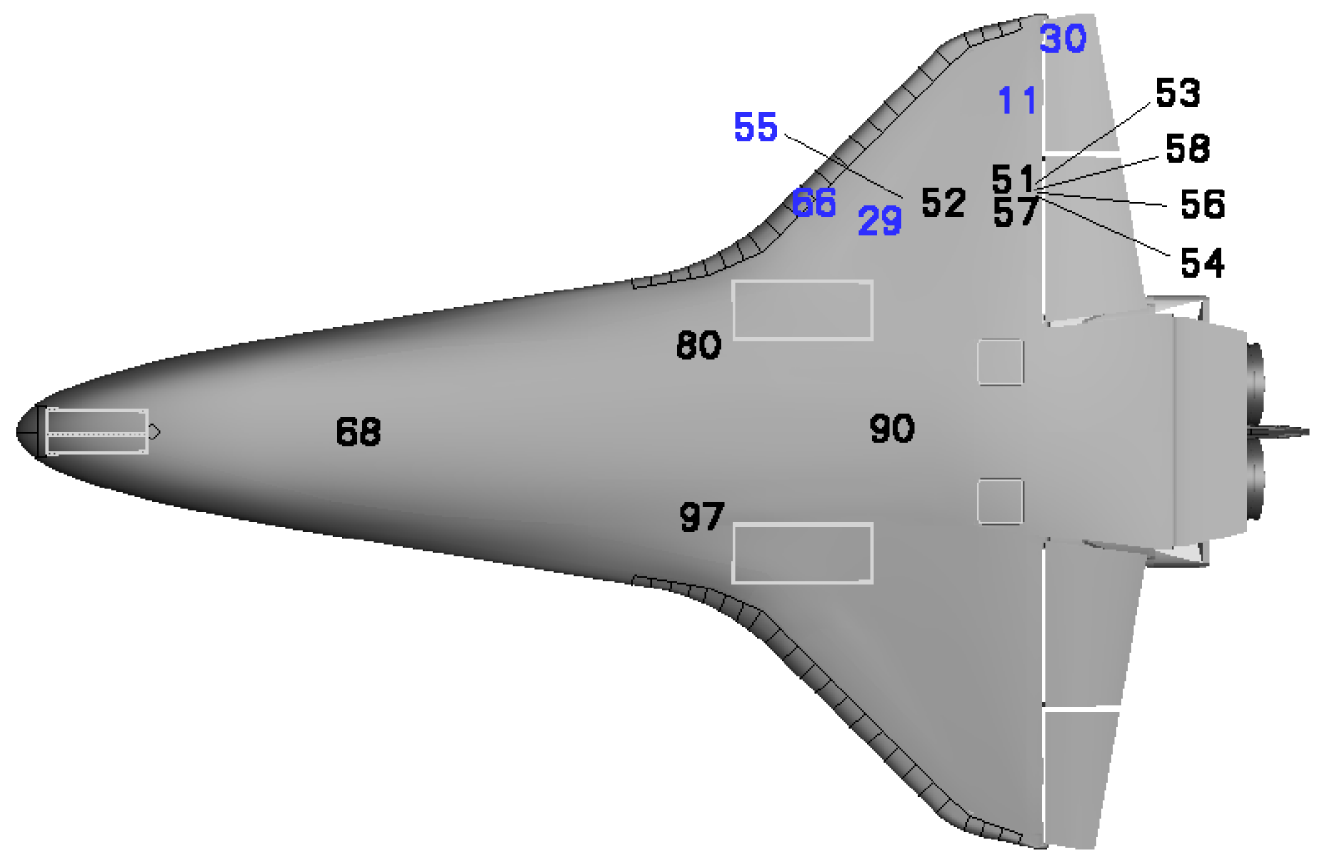

Figure 1. Thermocouple layout on Discovery, windward view. TC-29 is at the location of the flight experiment boundary layer trip. Blue text denotes thermocouples that were not used for the present accuracy assessment. 


\section{Experiment data}

Flight experiment data ${ }^{1}$ is available from 16 thermocouples on the windward side of the orbiter Discovery. The thermocouple names are listed in Table 1 and their placement on the orbiter are shown in Figure 1.

The thermocouples were installed on the orbiter thermal protection tiles, just under the tile RCG coating. The outside of the RCG coating constitutes the vehicle outer mold line (OML). Based upon previous thermal analyses performed within the orbiter engineering community, the temperature drop between the OML and the thermocouple installation point is approximately $20^{\circ} \mathrm{F}\left(10^{\circ} \mathrm{C}\right)$. Therefore, all measured thermocouple temperatures have been raised by $20^{\circ} \mathrm{F}$ in the present work (less than a $1 \%$ correction), for comparison with CFD predictions of the OML temperature. The thermocouple measurement uncertainty is estimated to have a standard deviation less than $1 \%$.

The flight experiment trip first produced boundary layer transition at approximately Mach 15.5, as inferred from jumps in the thermocouple temperature time histories. TC-51 is the thermocouple that exhibits the earliest transition; the TC-51 temperature time history is shown in Figure 2. Note: In all the thermocouple time history plots herein, such as Figure 2, the reentry trajectory traverses the Mach

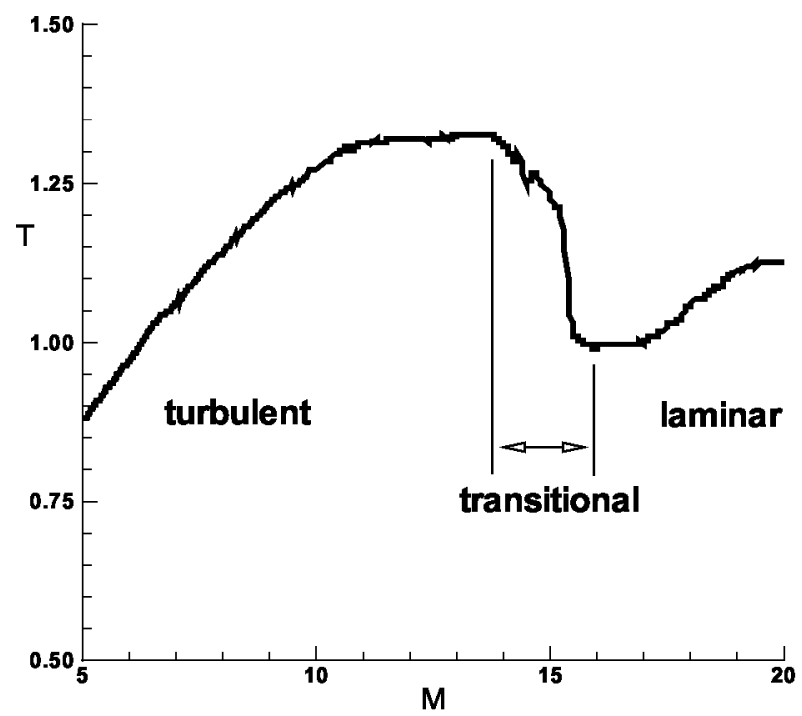

Figure 2. TC-51 time history: the thermocouple indicating the earliest turbulent flow. number domain monotonically from high to low, with the portion from Mach 20 to Mach 5 plotted. The temperature trends associated with the higher Mach numbers are indicative of laminar flow, whereas the temperature trends associated with the lower Mach numbers are indicative of turbulent flow; the boundary layer flow is assumed to be transitional between the laminar and turbulent periods. Turbulent, as opposed to transitional, boundary layer flow appears to be sustained on TC-51 below Mach 14 .

Geometry modeling assumptions for the CFD simulations rendered five of the thermocouples$11,29,30,55$, and 66 - unsuitable for the present assessment. TC-29 was mounted on the flight experiment protuberance whereas the CFD geometry has a smooth OML with no protuberance modeled (see Tang ${ }^{21}$ for CFD simulations of the protuberance). TC-55, which was positioned a short distance downstream of the protuberance. Its time history, Figure 3, is erratic, suggesting that its local flow was strongly disturbed by the protuberance. TC-66 was mounted within a half-inch of an RCC wing leading edge panel; the RCC-to-tile geometric transition is not modeled in the CFD surface grid and RCC material properties - catalycity, emissivity, and conduction-are all simulated by RCG properties for the simplicity of a uniform surface boundary condition. TC-30 was on the outboard port elevon; the elevon was actively deflected throughout the flight, whereas the CFD geometry model has the elevon in a constant fixed position.

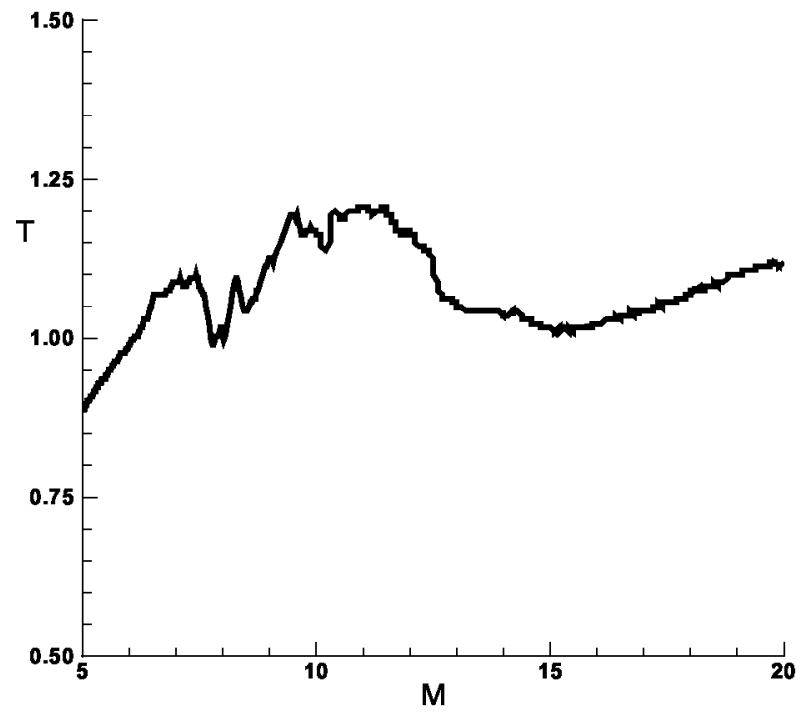

Figure 3. TC-55 time history. TC-11 was located just forward of the outboard port elevon. Although TC-11 was not on a deflected elevon, its laminar time history has trends that are out of character with the other thermocouple readings, except for a correlation with TC-30 at Mach 18-19, as shown in Figure 4. TC-11 experienced a late transition time and thus does not contribute much to the 

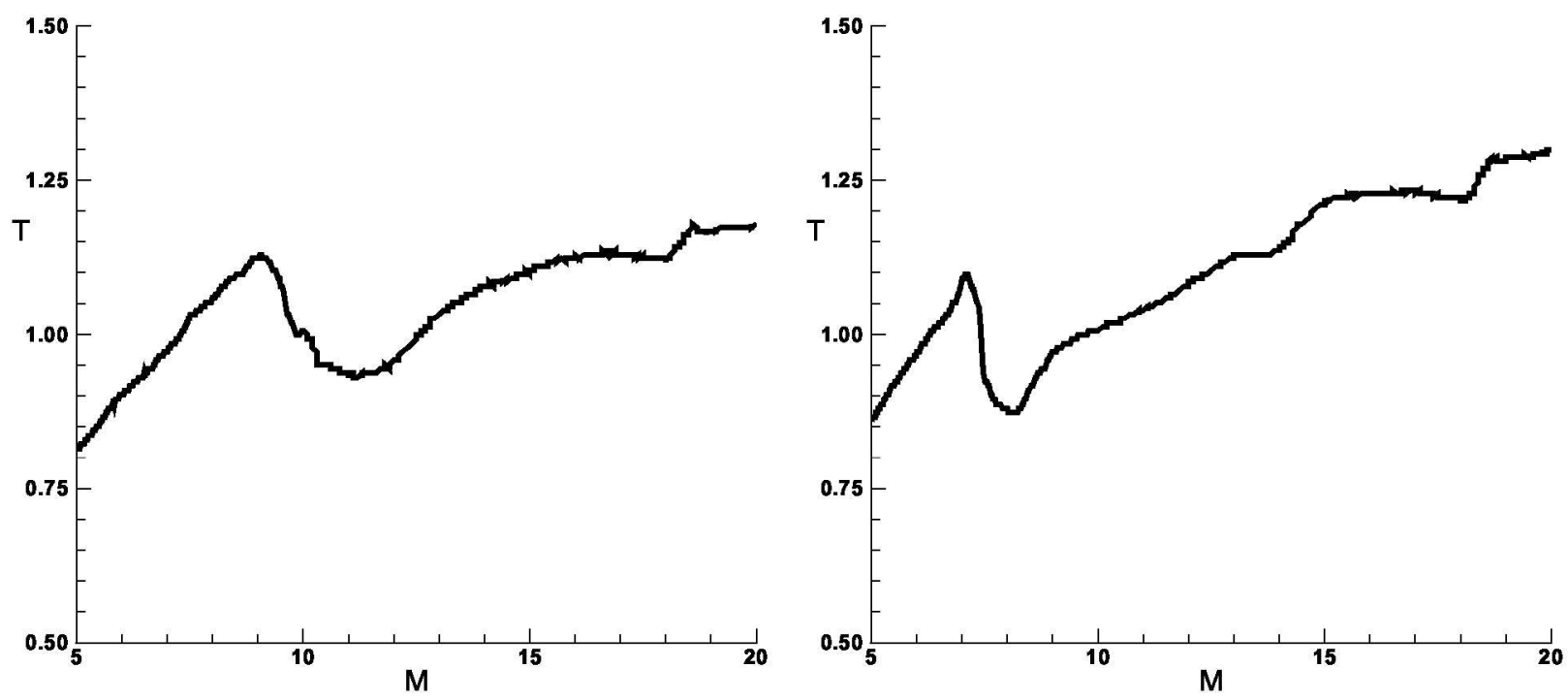

Figure 4. Thermocouple time histories: TC-30 (left) is on outboard port elevon, TC-11 (right) is just forward of the same elevon.

turbulent validation data set, and because of a possible influence from the elevon, TC-11 is omitted from the assessment. The remaining eleven thermocouples were used for the accuracy assessment.

The HYTHIRM team acquired off-board infrared images ${ }^{2}$ of Discovery over a portion of the STS-119 reentry flight path from a Department of Defense aerial asset. ${ }^{3}$ Figure 5 shows a frame from the raw HYTHIRM images, taken from approximately the point of closest approach between the orbiter and the imaging platform at Mach 8.4. The windward side of the orbiter is seen, with the small white triangular patch on the port wing being the region of turbulent flow produced by the flight experiment trip. The large swath of white covering the starboard wing is another region of turbulent flow, tripped by an unknown source near the nose landing gear door at approximately Mach 10.5.

The radiant intensities measured in the raw HYTHIRM images were converted into temperature measurements $^{4,5}$ and then mapped to a three-dimensional representation of the orbiter vehicle. In terms of highest spatial resolution and accuracy, the best trajectory point for comparison is Mach 8.4, with approximately 2foot spatial resolution. As the orbiter is about 100 feet long, this spatial resolution is approximately $2 \%$ of vehicle length. The HYTHIRM calibrations and view angles were optimized for best prediction accuracy of the windward tiles at the Mach 8.4 point. The uncertainty in mea-

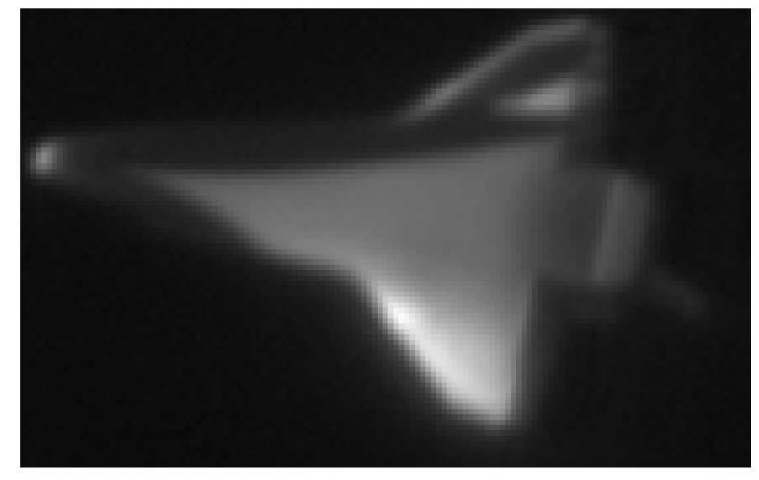

Figure 5. Raw HYTHIRM image frame (courtesy of HYTHIRM team). Brightness corresponds to higher radiant intensity. sured surface temperature is estimated at approximately 10 percent.

\section{CFD codes}

The Data Parallel Line-Relaxation (DPLR) software ${ }^{7}$ and the Langley Aerothermodynamic Upwind Relaxation Algorithm (LAURA) ${ }^{8,9}$ are both second-order accurate upwind finite-volume viscous-flow solvers, for use with block-structured grids. Air is modeled as five-species $\left(\mathrm{N}_{2}, \mathrm{O}_{2}, \mathrm{~N}, \mathrm{O}\right.$, and NO) in chemical non-equilibrium. The entire vehicle surface is modeled with reaction-cured glass catalysis ${ }^{10}$ and radiativeequilibrium temperatures based on an emissivity of 0.89 .

The simulations are either for fully-laminar or fully-turbulent boundary layers. Turbulent simulations 


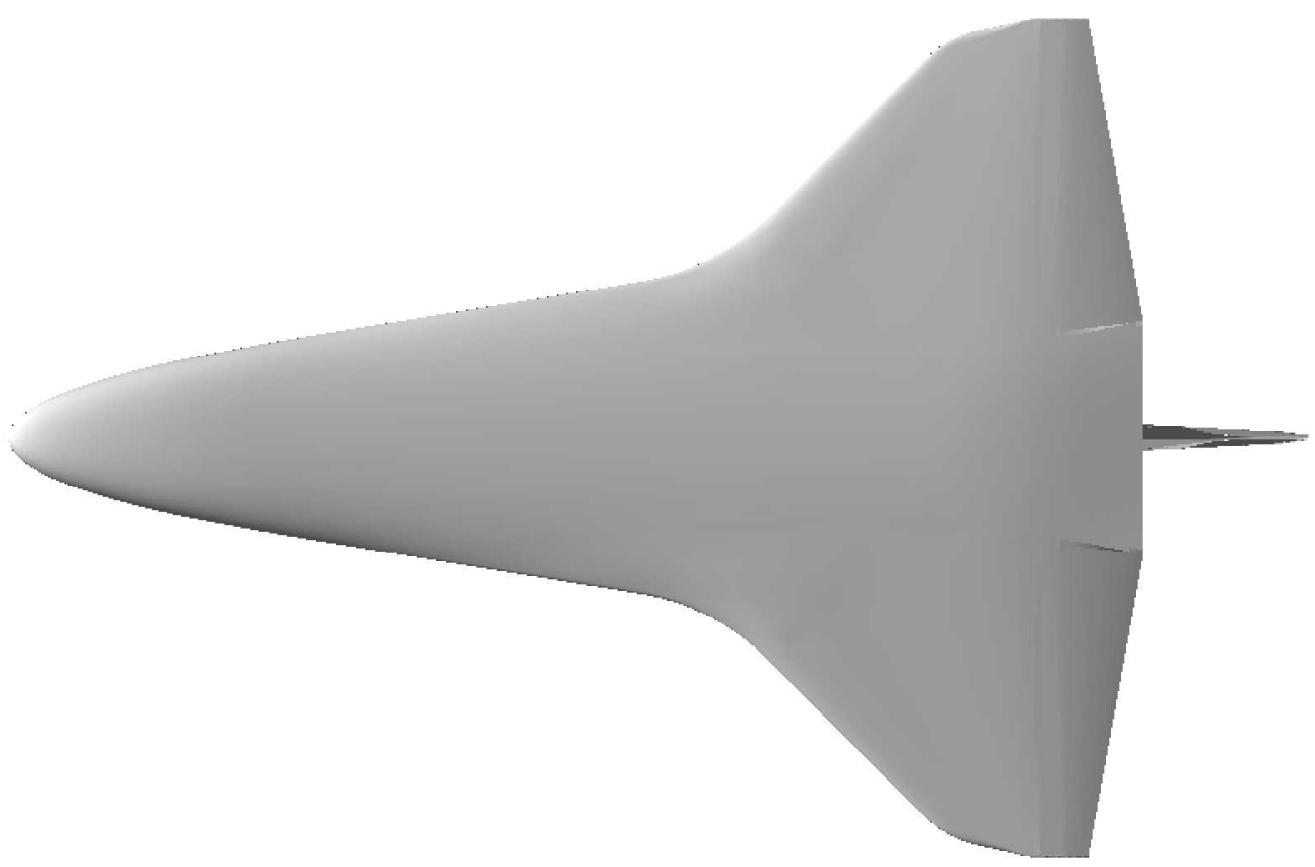

Figure 6. Windward plan-form of CFD vehicle geometry. Primary omission is the body flap.

are fully-turbulent from the nose, wetting the entire vehicle, using assumed steady-state Reynolds-averaged Navier-Stokes models. With DPLR, the algebraic Baldwin-Lomax ${ }^{11}$ and two-equation Shear-Stress Transport $^{12}$ turbulence models are employed. With LAURA, the algebraic Cebeci-Smith ${ }^{13}$ turbulence model is employed.

Previous laminar simulations of orbiter reentry flow fields, using the same CFD codes, have been reported in the context of the Columbia Accident Investigation ${ }^{14}$ and the subsequent Return-to-Flight program. ${ }^{15}$ During Return-to-Flight, comparisons to Mach-18 flight data from STS-2 showed surface temperature predictions from LAURA to average $2.7 \%$ low with coincidentally a $2.7 \%$ standard deviation; the DPLR surface temperatures averaged $0.6 \%$ low with a $3.2 \%$ standard deviation. Other applications of these codes to the orbiter vehicle have been reported, ${ }^{16-18}$ and additional context of the windward laminar flow fields is available in the literature. ${ }^{19,20}$

The computational volume grids contain about 12 million cells, and are solution-adapted for bow-shock alignment and boundary-layer clustering. Simplifications were made to the aft end of the vehicle, resulting in the windward plan-form shown in Figure 6. The elevons are undeflected, the elevon gaps are not modeled, the body flap is omitted, and the trailing edge of the elevons has been extended to meet the body-flap truncation. The main engine and orbital maneuvering nozzles are omitted. The flow-field domain encompasses the bow shock and ends at the wing trailing edge. The OML is smooth, with geometry perturbations smaller than a few inches quilted over. In particular, the boundary layer trip on the wing is not included in the CFD geometry; see Tang ${ }^{21}$ for CFD modeling of the boundary layer trip. The flight experiment protuberance is not modeled and the RCC structures are not distinctly modeled. These differences can be seen by contrasting Figure 6 with Figure 1.

In addition to the primary DPLR and LAURA CFD codes, the Loci-CHEM ${ }^{22,23}$ code was used for a single Mach number, 9.1, on an unstructured grid. The present authors are inexperienced with Loci-CHEM as compared to DPLR and LAURA, so the Loci-CHEM results are not included in the statistical accuracy assessments that follow. However, unstructured-grid CFD methods are rapidly approaching the existing structured-grid CFD accuracy and robustness for viscous hypersonic simulations, ${ }^{6,24-26}$ and the present Loci-CHEM results are included as a contribution toward unstructured-grid maturation from an applications perspective. Loci-CHEM was operated as a nominally second-order accurate viscous flow solver with 5 -species non-equilibrium chemistry. The surface temperature boundary condition was the same radiative equilibrium condition as used with DPLR and LAURA, but the surface was non-catalytic because a partially catalytic 
DPLR LAURA

\begin{tabular}{|c|c|c|c|c|c|c|c|c|}
\hline Mach & $h, \mathrm{~km}$ & $\alpha,^{\circ}$ & $\beta, \circ$ & laminar & Baldwin-Lomax & SST & laminar & Cebeci-Smith \\
\hline 19.4 & 66.0 & 39.2 & 0.06 & yes & & & yes & \\
\hline 17.0 & 62.6 & 42.1 & 0.48 & yes & & & & \\
\hline 13.5 & 56.2 & 39.0 & -0.03 & yes & yes & yes & yes & yes \\
\hline 12.9 & 55.5 & 39.3 & 0.14 & & yes & & & \\
\hline 10.5 & 52.3 & 39.2 & 0.17 & & yes & & & \\
\hline 9.1 & 49.9 & 38.3 & 0.24 & yes & yes & yes & yes & yes \\
\hline 8.4 & 49.0 & 37.6 & 0.12 & yes & yes & & & \\
\hline 7.5 & 46.7 & 35.2 & 0.02 & & yes & & & \\
\hline 5.8 & 40.2 & 28.0 & 0.03 & yes & yes & & yes & yes \\
\hline
\end{tabular}

Table 2. STS-119 trajectory points and case matrix. Flight sideslip angles are listed, but all CFD simulations set $\beta=0$.

condition was lacking. The unstructured grid contained tetrahedrons, prisms, and pyramids with 17.5 million cells. Both laminar and SST simulations were performed.

\section{Cases}

Nine STS-119 trajectory points were considered and are listed in Table 2. A mix of laminar and turbulent simulations were performed using DPLR and LAURA. Results from the algebraic turbulence models in DPLR and LAURA were similar, so full overlap of cases with both codes was not necessary. All simulations were performed at the post-flight reconstructed STS-119 trajectory conditions, with the exception of sideslip; all CFD simulations set $\beta=0$ to benefit from the computational efficiency of a plane of symmetry on the vehicle centerline.

The Mach 8.4 trajectory point was used for comparison with the HYTHIRM data, but is also included in the statistical accuracy assessment versus the thermocouple measurements.

Turbulent simulations using the two-equation SST model were performed with DPLR at the Mach 9.1 and 13.5 trajectory points, and with Loci-CHEM at the Mach 9.1 point.

\section{Verification}

The current CFD solution process followed best-practices established during the space shuttle Return-toFlight program. ${ }^{15}$ In reference 15, quadrupling the computational grid tangentially to the surface decreased the computed surface temperatures by $0.06 \%$ on average. Doubling the computational grid in the surfaceperpendicular direction decreased the computed surface temperatures by $1.11 \%$ on average.

A partial verification of the chemistry models was performed by repeating the Mach-6 laminar and turbulent cases with perfect gas air. The differences in heating rates, sampled at 11 thermocouple locations, were all less than $0.03 \%$ between the perfect-gas and five-species air models, for both laminar and turbulent simulations. Surface temperatures were indistinguishable between the perfect-gas and five-species results.

Code-to-code comparisons between DPLR and LAURA were performed at four laminar and three turbulent overlap points. Predictions from both codes agreed very closely as shown in the following Results section.

\section{Results}

Two types of comparisons are possible with the flight data, discrete and acreage. Thermocouples are compared at discrete surface locations, averaged over all the appropriate sensors and trajectory points, to produce quantitative accuracy assessments. The HYTHIRM data is a global picture at a single trajectory point, Mach 8.4; acreage qualitative comparisons are made. 


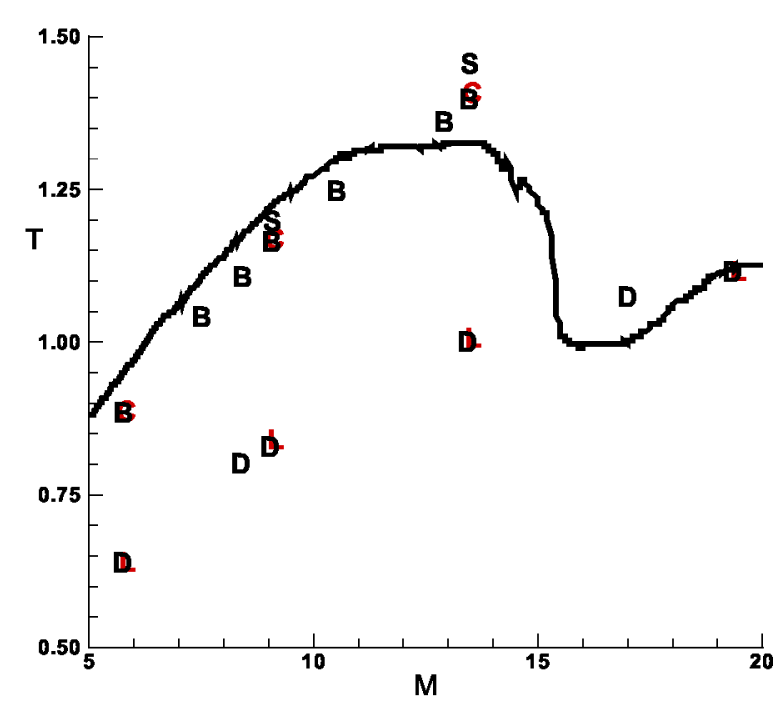

(a) TC-51.

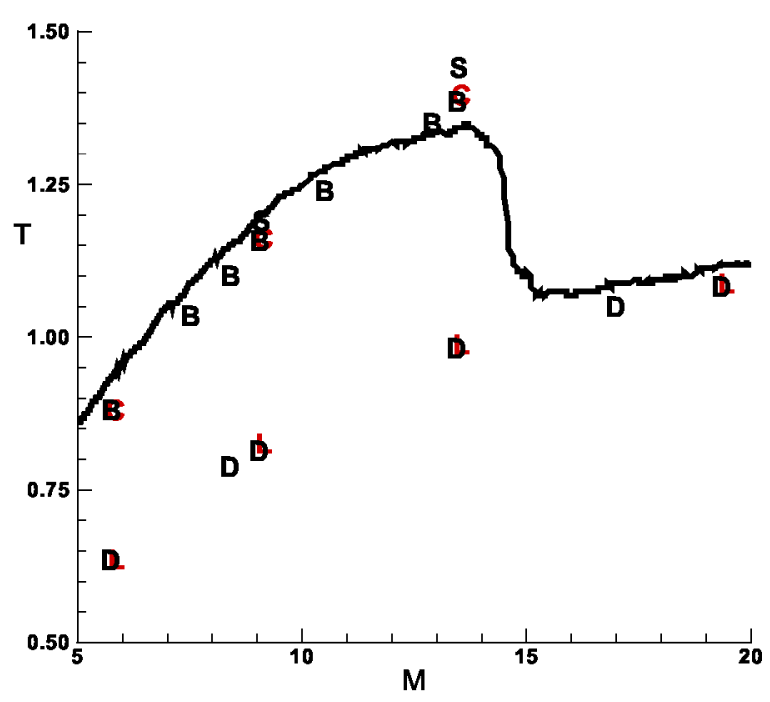

(b) TC-53.

Figure 7. TC-51 and TC-53 temperatures. Line is thermocouple measurement; $D=$ laminar DPLR; $L=$ laminar LAURA; $\mathbf{B}=$ Baldwin-Lomax; $\mathbf{C}=$ Cebeci-Smith; and $\mathbf{S}=\mathbf{S S T}$.

\section{A. Thermocouples}

The temperature time histories for the eleven thermocouples in the upper half of Table 1 follow as Mach number versus non-dimensional temperature plots. DPLR and LAURA surface temperature predictions from both laminar and turbulent simulations are included on the plots. The lower trend of CFD predictions correspond to laminar simulations and the upper trends correspond to turbulent simulations. In the timehistory plots, the data line is the thermocouple measurement that has been adjusted to estimate the OML temperatures as described in Section II; laminar CFD results are designated by ' $D$ ' for DPLR and ' $L$ ' for LAURA; and turbulent CFD results are designated by 'B' for the Baldwin-Lomax model with DPLR, 'C' for the Cebeci-Smith model with LAURA, and 'S' for the SST model with DPLR. Overlapping CFD data points

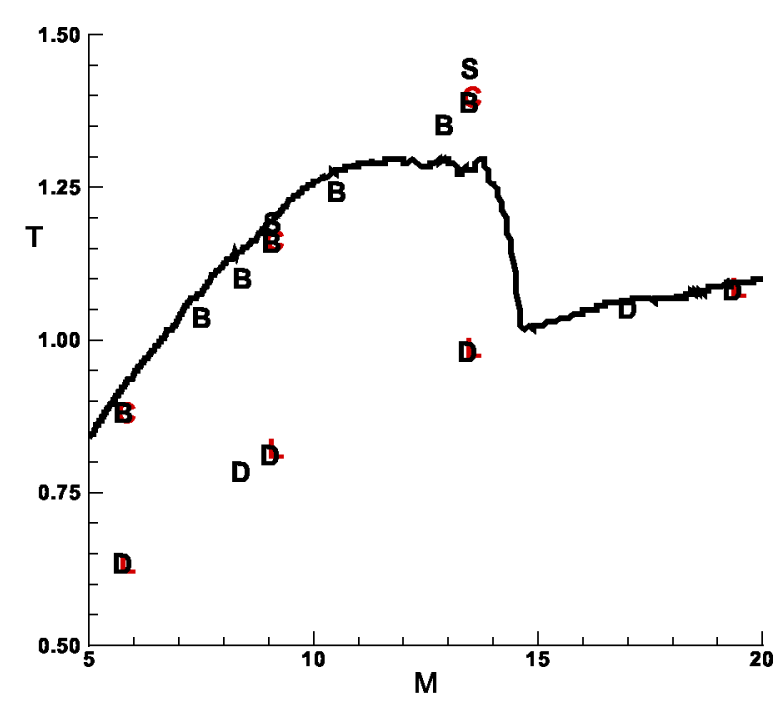

(a) TC-58.

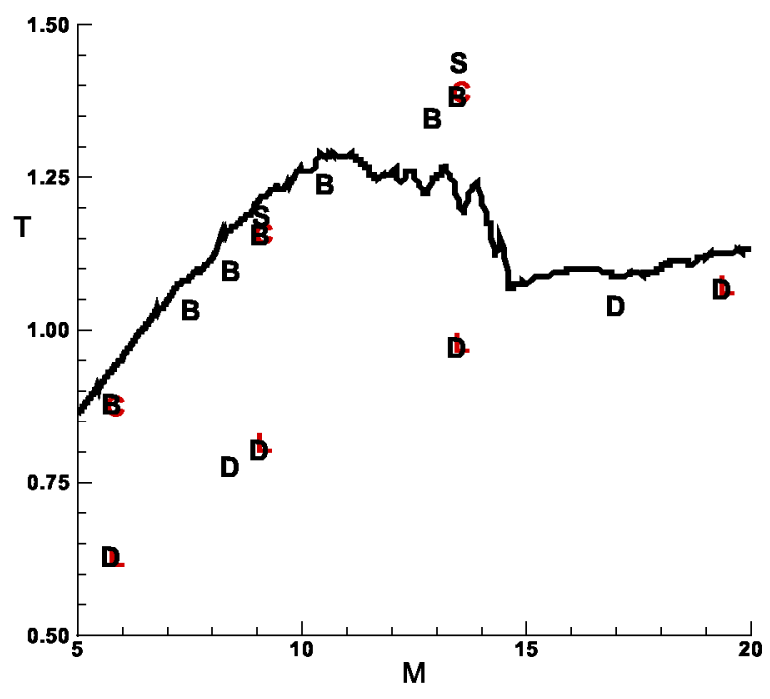

(b) TC-56.

Figure 8. TC-58 and TC-56 temperatures. Line is thermocouple measurement; $D=$ laminar DPLR; L $=$ laminar LAURA; B = Baldwin-Lomax; $\mathbf{C}=$ Cebeci-Smith; and $\mathbf{S}=\mathbf{S S T}$. 


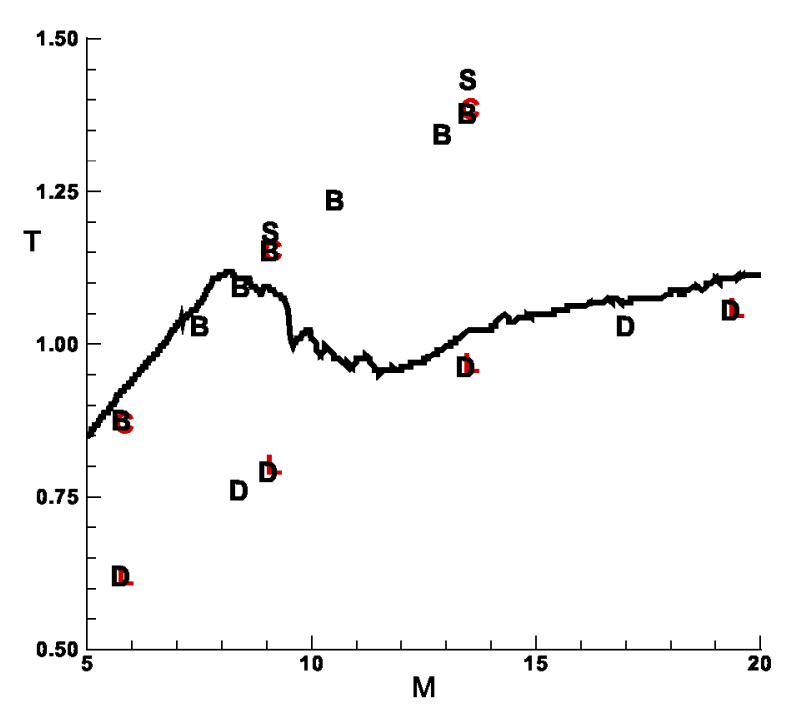

(a) TC-54.

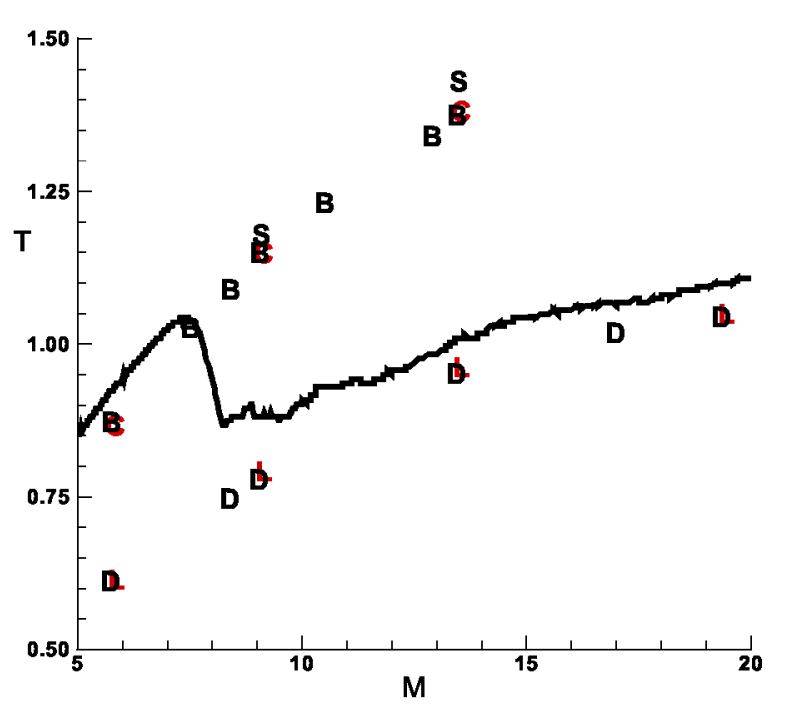

(b) TC-57.

Figure 9. TC-54 and TC-57 temperatures. Line is thermocouple measurement; $D=$ laminar $D P L R ; L=$ laminar LAURA; B = Baldwin-Lomax; $\mathbf{C}=$ Cebeci-Smith; and $\mathbf{S}=\mathbf{S S T}$.

in the plots have been jittered ${ }^{27}$ by \pm 0.05 Mach to improve visibility. In the discussion of each thermocouple, the Mach number ranges for laminar and turbulent flow are identified.

TC-51 indicated the earliest boundary layer transition, beginning at approximately Mach 15.5, shown in Figure 7(a). This thermocouple was positioned directly downstream of the trip, as predicted by CFDsimulated boundary layer edge velocity streamlines, so as to be in the center of the induced turbulent wedge. For the accuracy assessments, all turbulent CFD points are retained. But none of the laminar CFD points are retained; the laminar thermocouple response is atypical, perhaps as a result of a protuberance-induced vortical flow. The turbulent thermocouple response exhibits a distinct change in trend at approximately Mach 11 that is not present in the CFD predictions. The thermocouple temperatures remain constant over Mach 11-14, whereas the CFD predictions increase continually with Mach number. This divergence invalidates any attempt to extrapolate the turbulent CFD accuracy assessment in the present report to higher Mach numbers.

TC-53 was located adjacent to TC-51 on the inboard side, and shows a transition time slightly delayed from TC-51, Figure 7(b). For TC-53, all of the turbulent CFD cases were used for the accuracy assessment, along with the two laminar Mach numbers greater than 15. TC-53 shows a change in measured turbulent trend at about Mach 11, but the change is not as dramatic as was seen for TC-51.

TC-58 was located inboard of TC-53, and experienced an early transition, at about Mach 14.5, Figure 8(a). The turbulent assessment used all of the turbulent Mach numbers. The laminar assessment used the highest two Mach numbers. Again, a change in measured turbulent-flow thermocouple temperature trend is evident at about Mach 11, which is not seen in the CFD predictions. The CFD and thermocouple temperatures are diverging with increasing Mach number.

TC-56 was located inboard of TC-58, and indicates boundary layer transition beginning about Mach 14, but with an extended period of transitional flow where the edge of the wedge of turbulent flow appears to oscillate back and forth over the thermocouple location, Figure 8(b). Mach numbers less than 11 were used for the turbulent assessment, and Mach numbers above 15 were used for the laminar assessment. Mach numbers of $11-15$ were omitted, being deemed transitional.

TC-54 was located inboard of TC-56, and does not indicate boundary layer transition until about Mach 11, and then has a lengthy transitional time, Figure 9(a). Only the lowest two Mach numbers from TC-54 were used in the turbulent accuracy assessment; the Mach-8.4 point was not used because the thermocouple temperature does not appear to be quite at the fully turbulent level. The highest three Mach numbers were used in the laminar assessment.

TC-57 was located inboard of TC-54, and appears to have been generally outside of the protuberanceinduced turbulent wedge, Figure 9(b). The lowest two turbulent Mach numbers were used in the accuracy 
assessment, along with the highest three laminar Mach number points.

TC-52 was located between the boundary layer trip and TC-51. The laminar portion of the thermocouple trace suggests evidence of a protuberance-induced vortical flow passing back and forth over the thermocouple location, Figure 10. Thus the laminar-flow Mach number points are not included in the accuracy assessment. The transition to turbulence does not appear to be a cleanly achieved as at the TC-51 location, so only Mach numbers less than 11 were used for the turbulent accuracy assessment.

TC-68 and TC-90 were both located on the vehicle centerline. TC-68 was at approximately a quarter of the vehicle length from the nose, and TC-90 was at approximately three-quarters of the vehicle length. At TC-68, boundary layer transition appears to begin at about Mach 9, Figure 11(a). Only the lowest turbulent-flow Mach number was used with TC-68 in the assessment; laminar-flow Mach numbers greater than 9 were used in the assessment.

Further aft on the vehicle centerline at TC-90, boundary layer transition appears to begin a little earlier at about Mach 10.5, Figure 11(b). The Mach number points less than 10 were used in the turbulent assessment. The Mach number points greater than 10 were used in the laminar assessment.

TC-80 was located on the port side, about midlength. The thermocouple history, Figure 12(a), is similar to TC-68. Only the lowest turbulent-flow Mach number was used in the assessment; all but the lowest Mach number was used in the laminar assessment.

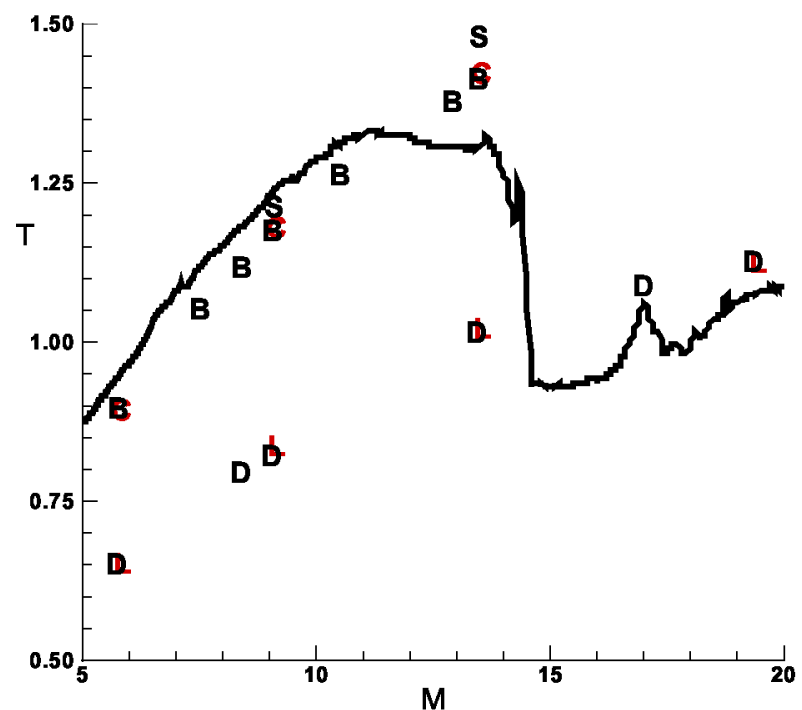

Figure 10. TC-52 temperatures. Line is thermocouple measurement; $\mathbf{D}=$ laminar DPLR; $\mathbf{L}=$ laminar LAURA; B = Baldwin-Lomax; $C=$ Cebeci-Smith; and $\mathbf{S}=\mathbf{S S T}$.

TC-97 was located as the starboard mirror of TC-80, but experienced transition a little earlier, at Mach 10.5, Figure 12(b). The Mach number points less than 10 were used in the turbulent assessment. The Mach number points greater than 10 were used in the laminar assessment.

The accuracy of the CFD predictions with algebraic turbulence models is summarized in Table 3 . Results

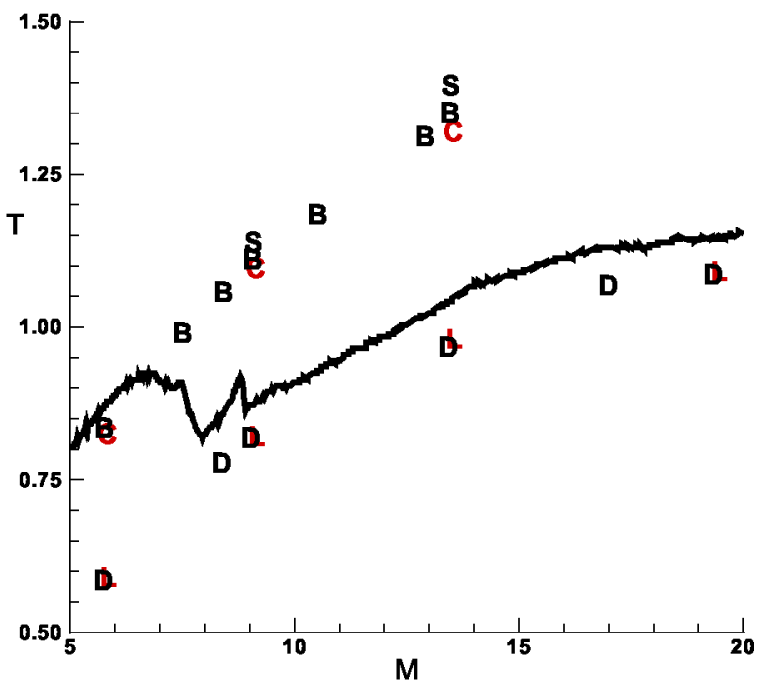

(a) TC-68.

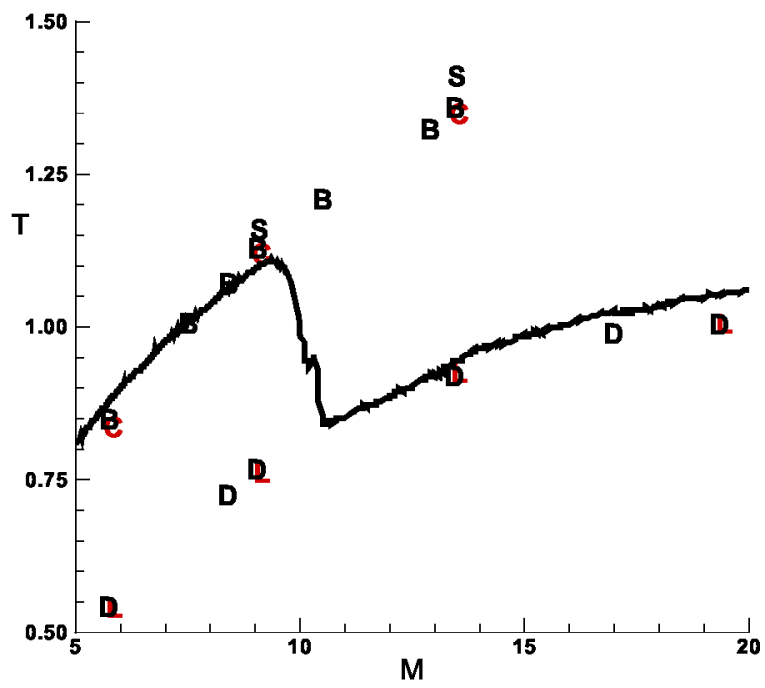

(b) TC-90.

Figure 11. TC-68 and TC-90 temperatures. Line is thermocouple measurement; $D=$ laminar DPLR; $L=$ laminar LAURA; B = Baldwin-Lomax; C = Cebeci-Smith; and S = SST. 


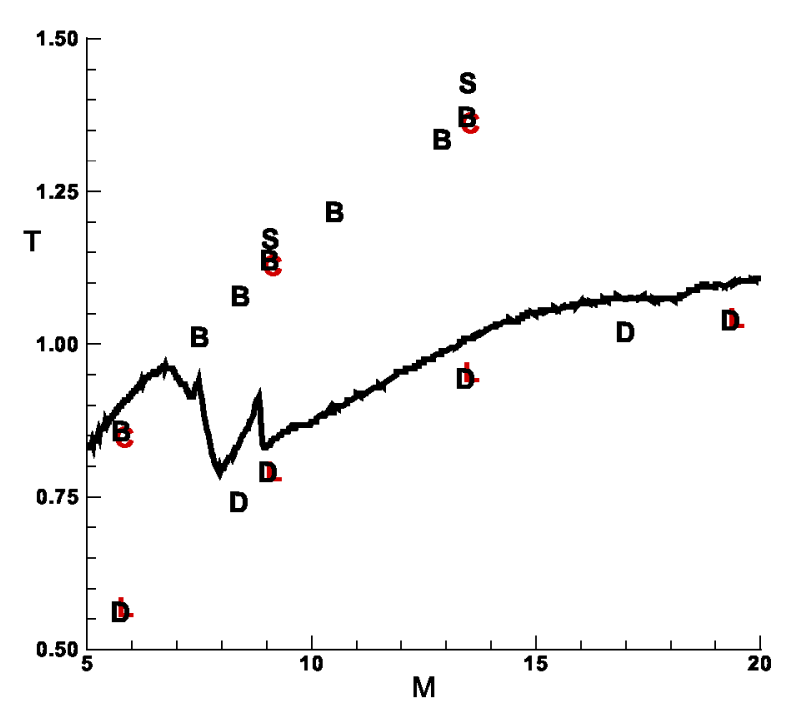

(a) TC-80.

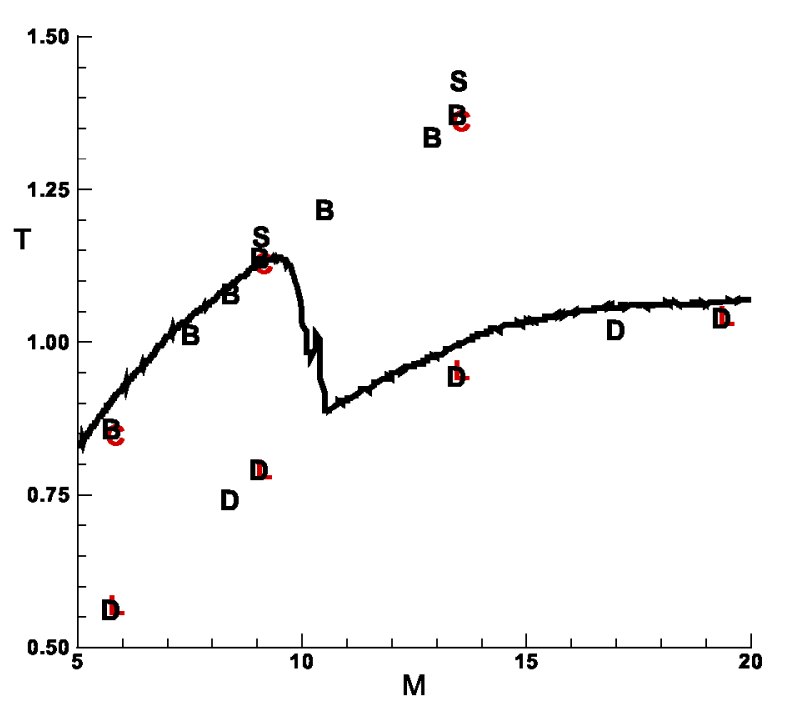

(b) TC-97.

Figure 12. TC-80 and TC-97 temperatures. Line is thermocouple measurement; $D=$ laminar DPLR; $L=$ laminar LAURA; B = Baldwin-Lomax; $\mathbf{C}=$ Cebeci-Smith; and $\mathbf{S}=\mathbf{S S T}$.

from both the Baldwin-Lomax and Cebeci-Smith models were similar, showing a bias to under-predict surface temperatures across all Mach numbers by 3.1\%, with a $3.9 \%$ standard deviation. Considering only Mach numbers less than 11, the CFD predictions average $4.3 \%$ low, with a $2.1 \%$ standard deviation. For turbulent flow at Mach numbers greater than 11, the relative agreement is reversed: the algebraic models over predict surface temperatures by $5.1 \%$ on average, with a $2.8 \%$ standard deviation.

For comparison, the laminar CFD predictions averaged a $4.5 \%$ under-prediction bias, with a $1.7 \%$ standard deviation. The laminar CFD-to-measurement agreement was consistent across the Mach number range, without the change in trends seen for the turbulent comparisons. The laminar comparisons in the present assessment were made at higher Mach numbers than the turbulent comparisons, and thus include larger chemical and compressibility effects.

Simulations were performed using the two-equation SST turbulence model at Mach 9.1 and 13.5 using DPLR. At Mach 9.1, the SST surface temperatures were consistently 3.0\% higher than the Baldwin-Lomax surface temperatures, eliminating much of the under-prediction bias observed in the algebraic models. At Mach 13.5, the SST surface temperatures were consistently $4.2 \%$ higher than the Baldwin-Lomax temperatures, exacerbating the divergence seen between prediction and measurement for the few thermocouples that experienced turbulent flow at this Mach number.

An additional SST simulation was performed with the Loci-CHEM code at Mach 9.1. The Loci-CHEM simulation employed an unstructured grid, as opposed to the structured grids that have traditionally been used for hypersonic viscous flow modeling. The present authors are not proficient with Loci-CHEM to the extent as they are with DPLR and LAURA, and therefor have not included the Loci-CHEM results in the previously discussed accuracy assessments. As a consequence of the lack of proficiency the Loci-CHEM domain omitted the aft $20 \%$ of the orbiter vehicle to avoid modeling difficulties associated with the Orbital Maneuvering System pods and the vertical tail. Despite these caveats, the results for the windward side fuselage were encouraging. The laminar Loci-CHEM surface temperatures were comparable to the DPLR temperatures at the TC-68 and TC- 80 locations, being approximately $2 \%$ higher. The turbulent SST Loci-

$\begin{array}{lccc}\text { Mach range } & 5.8-13.5 & 5.8-10.5 & 12.9-13.5 \\ \text { Average error, \% } & -3.1 & -4.3 & 5.1 \\ \text { Standard deviation, \% } & 3.9 & 2.1 & 2.8\end{array}$

Table 3. Algebraic turbulence model (Baldwin-Lomax and Cebeci-Smith) surface-temperature accuracy assessment. Mach 11 separates under- and over-prediction. 
Baldwin-Lomax (simulation)

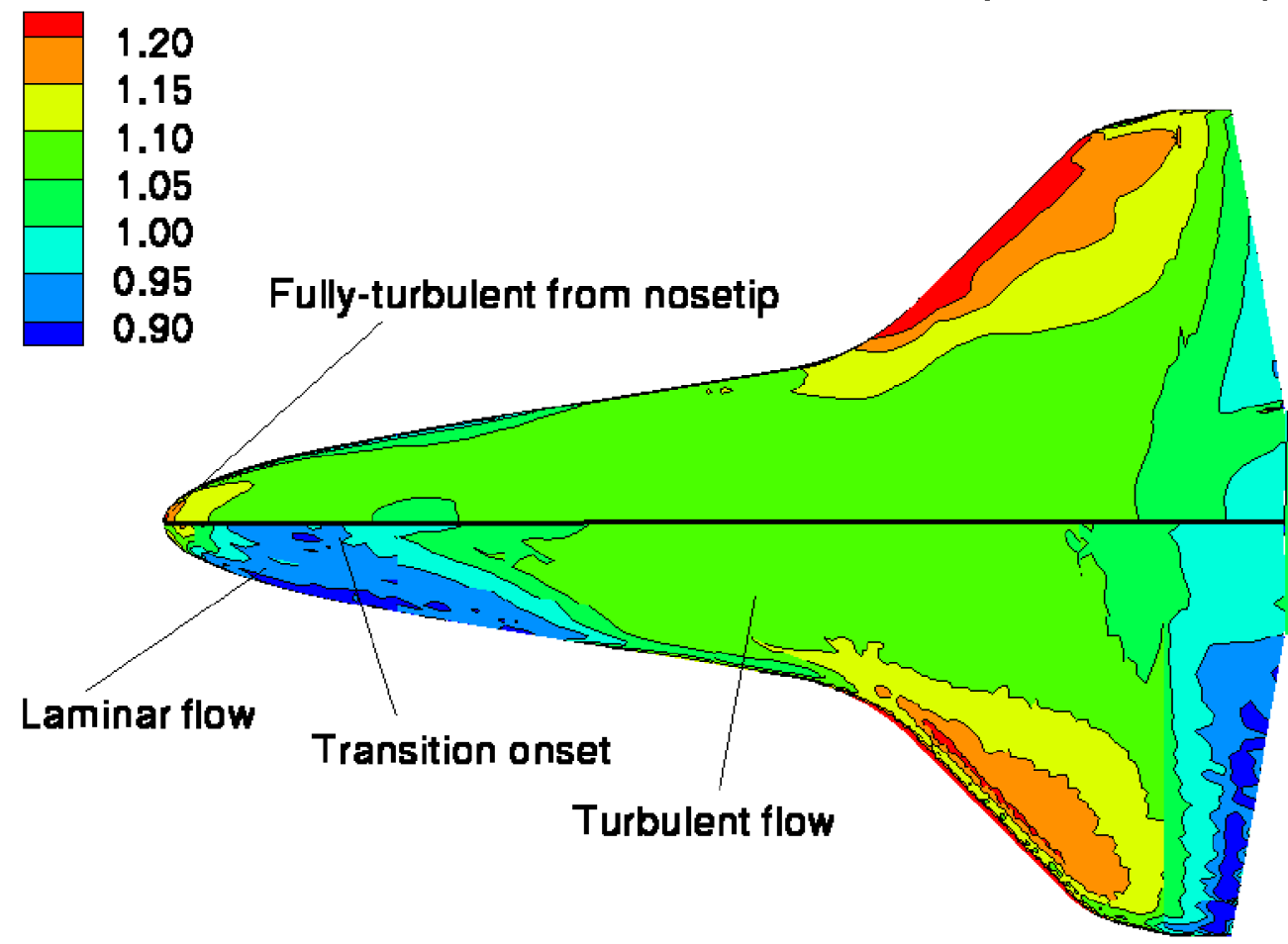

\section{HYTHIRM (flight)}

Figure 13. HYTHIRM flight temperature measurement (bottom) and DPLR Baldwin-Lomax turbulent simulation (top).

CHEM surface temperature matched the DPLR SST temperature at the TC-90 location and was $2 \%$ lower than the DPLR SST temperature at the TC-97 location.

\section{B. HYTHIRM}

For the Mach 8.4 trajectory point, the fully-turbulent DPLR simulation using the Baldwin-Lomax model is compared to the flight surface temperatures as measured by HYTHIRM $^{28}$ in Figure 13. Toward the nose of the HYTHIRM image relatively low surface temperatures are seen, indicative of laminar boundary layer flow. The surface temperatures rise in a wedge-like pattern starting at about $20 \%$ of the vehicle length, characteristic of a discrete roughness element transitioning the boundary layer flow to turbulence. Note that the trip element for this Mach 8.4 condition is not the same as the flight-experiment trip that was installed on the port wing. The corresponding CFD simulation lacks this fore-body laminar flow, with turbulence simplistically enforced from the nose. See Candler $^{6}$ for a more physically realistic modeling of the transition front for the this same case.

Further differences between the HYTHIRM image and the CFD simulation are seen on the elevons at the trailing edge of the vehicle. At this point in the trajectory, the orbiter's elevons were deflected upward, whereas the elevons are undeflected in the CFD geometry model, accounting for the elevated predicted elevon temperatures in the CFD simulation relative to the HYTHIRM measurement. Also, the HYTHIRM image is erratic along the wing leading edge, in part due to spatial resolution and view angle limitations.

Aside from the above mentioned areas, the simulation is seen to match the measurements within about $5 \%$ (the contour spacing) and to have a qualitative agreement such as in the shape and extent of the yellow and orange contour bands.

Figure 14(a) presents centerline surface temperatures from both the HYTHIRM and Baldwin-Lomax 


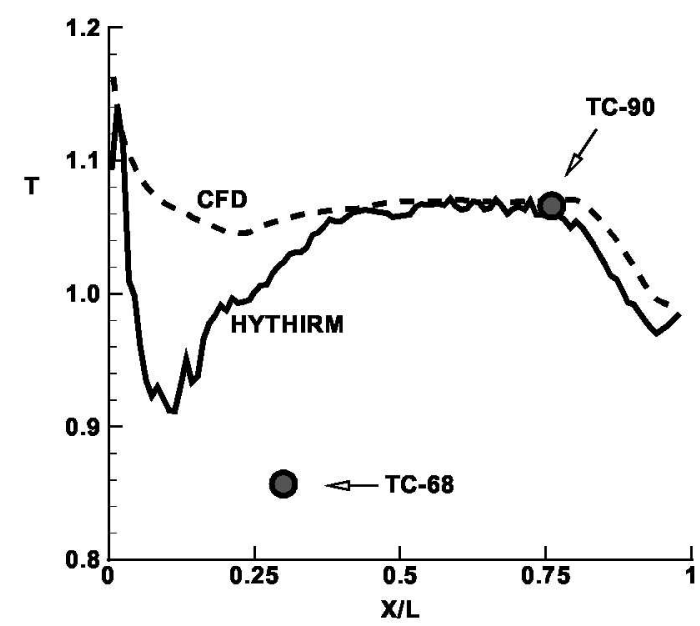

(a) Centerline cut.

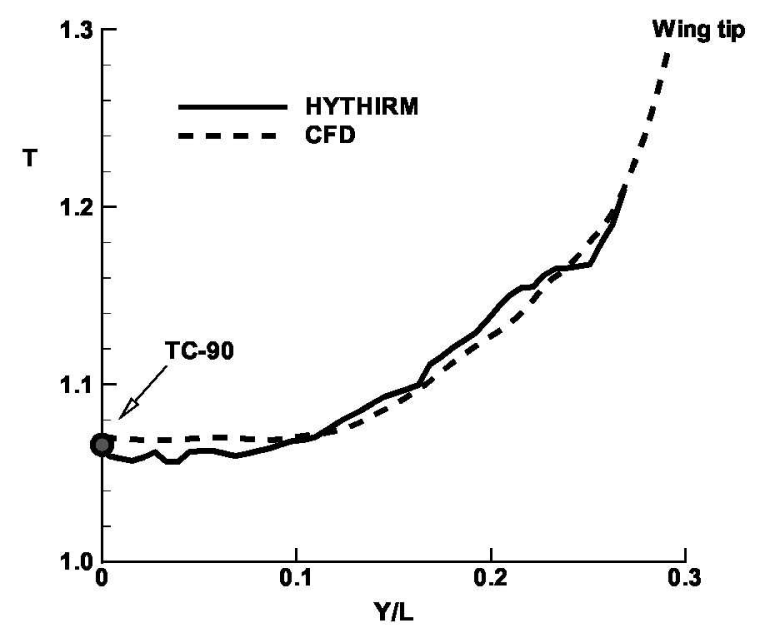

(b) Span-wise cut at TC-90 axial location.

Figure 14. HYTHIRM (solid) and Baldwin-Lomax CFD (dashed) surface temperature slices.

DPLR data sets. The measurements from the centerline thermocouples TC-68 and TC-90 are included. The relatively low temperatures over the forward quarter of the vehicle are indicative of laminar and transitional flow. Fully-developed turbulence appears to be established by about $X / L=40 \%$. The agreement between CFD, HYTHIRM, and the TC-90 reading is very good, within 1-2\%. The drop in heating over the aft fifth of the vehicle is due to an up-sweep in the OML. There does appear to be a spatial offset between the mapped HYTHIRM data and the CFD geometry, evident in the horizontal shift between the plot lines toward $X / L=1$.

Another view of the comparison between the CFD simulation and the HYTHIRM data is presented in Figure 14(b), where a line cut in the span-wise direction has been taken of the surface temperatures at the axial location of TC-90. Recall that TC-90 was on the centerline at approximately three-quarters of the vehicle length, Figure 1. Both the HYTHIRM measurement and the CFD prediction are seen to agree closely with the thermocouple measurement on the centerline. Off centerline the CFD prediction closely tracks the HYTHIRM measurement out toward the wing tip, within 1-2\%.

\section{Summary of results}

STS-119 provides a rare opportunity to assess turbulent CFD models against high-Mach-number turbulent flight data. The boundary layer transition experiment that had been conducted during the STS-119 reentry consisted of a fixed-height boundary layer trip fashioned out of high-temperature capable thermal protection material and a thermocouple instrumentation system that measured surface temperatures. In addition, off-board infrared telemetry had been obtained by the Hypersonic Thermodynamic Infrared Measurement (HYTHIRM) team, producing temperature maps of the orbiter vehicle.

Turbulent surface temperature predictions from CFD codes employing algebraic turbulence models, the DPLR code with the Baldwin-Lomax model and the LAURA code with the Cebeci-Smith model, were shown to agree closely with one another and to average $3.1 \%$ low as compared to eleven thermocouple measurements over Mach 5.8-13.5. The CFD temperature trends with Mach number are similar to the measured trends for Mach numbers below 11, but the predicted and measured trends diverge for Mach numbers greater than 11. For Mach numbers less than 11, the predictions with algebraic models averaged $4.3 \%$ low. But for Mach numbers greater than 11 the predictions averaged $5.1 \%$ high.

For context, the laminar CFD accuracy was also assessed, showing the CFD surface temperature predictions to be biased $4.5 \%$ low.

CFD simulations were also performed using the SST two-equation turbulence model in DPLR at Mach 9.1 and 13.5 conditions. Surface temperatures from the SST model were consistently higher than the Baldwin- 
Lomax temperatures, by $3.0 \%$ at Mach 9.1 and $4.2 \%$ at Mach 13.5 .

Comparisons to the HYTHIRM measurements at Mach 8.4 show good agreement on the fuselage acreage, lending credence to the statistical comparisons versus the thermocouple data at discrete locations. Two main shortfalls of the present CFD modeling are manifested by the HYTHIRM comparison: the laminar fore-body flow and boundary layer transition front are not present in the CFD simulation, and the elevon deflections are not included in the geometry model.

\section{References}

${ }^{1}$ Anderson, B., "BLT Flight Experiment Overview and In-Situ Measurements," AIAA Paper 2010-240, Jan. 2010.

${ }^{2}$ Horvath, T. J., Tomek, D. M., Berger, K. T., Zalameda, J. N., Splinter, S. C., and Krasa, P. W., "The HYTHIRM Project: Flight Thermography of the Space Shuttle during Hypersonic Re-entry," AIAA Paper 2010-241, Jan. 2010.

${ }^{3}$ Tack, S., Tomek, D. M., Horvath, T. J., Verstynen, H. A., and Shea, E. J., "Cast Glance Near Infrared Imaging Observations of the Space Shuttle during Hypersonic Re-entry," AIAA Paper 2010-243, Jan. 2010.

${ }^{4}$ Zalameda, J. N., Horvath, T. J., Tomek, D. M., Tietjen, A. B., Gibson, D. M., Taylor, J. C., Tack, S., Bush, B. C., Mercer, C. D., and Shea, E. J., "Application of a Near Infrared Imaging System for Thermographic Imaging of the Space Shuttle during Hypersonic Re-entry," AIAA Paper 2010-245, Jan. 2010.

${ }^{5}$ Gibson, D. M., Spisz, T. S., Taylor, J. C., Zalameda, J. N., Horvath, T. J., Tomek, D. M., Tietjen, A. B., Tack, S., and Bush, B. C., "HYTHIRM Radiance Modeling and Image Analyses in Support of STS-119, STS-125, and STS-128 Space Shuttle Hypersonic Re-entries," AIAA Paper 2010-244, Jan. 2010.

${ }^{6}$ Candler, G. V. and Campbell, C., "Hypersonic Navier Stokes Comparisons to Orbiter Flight Data," AIAA Paper 2010455, Jan. 2010.

${ }^{7}$ Wright, M. J., Candler, G. V., and Bose, D., "Data-Parallel Line Relaxation Method for the Navier-Stokes Equations," AIAA Journal, Vol. 36, No. 9, Sept. 1998, pp. 1603-1609.

${ }^{8}$ Gnoffo, P. A., Gupta, R. N., and Shinn, J. L., "Conservation Equations and Physical Models for Hypersonic Air Flows in Thermal and Chemical Nonequilibrium," NASA TP 2867, Feb. 1989.

${ }^{9}$ Gnoffo, P. A., "An Upwind-Biased, Point-Implicit Relaxation Algorithm for Viscous, Compressible Perfect-Gas Flows," NASA TP 2953, Feb. 1990.

${ }^{10}$ Stewart, D. A., "Surface Catalysis and Characterization of Proposed Candidate TPS for Access-to-Space Vehicles," NASA TM 112206, 1997.

${ }^{11}$ Baldwin, B. S. and Lomax, H., "Thin Layer Approximation and Algebraic Model for Separated Turbulent Flows," AIAA Paper 78-257, January 1978.

${ }^{12}$ Menter, F. R., "Two-Equation Eddy-Viscosity Turbulence Models for Engineering Applications," AIAA Journal, Vol. 32, No. 8, Aug. 1994, pp. 1598-1605.

${ }^{13}$ Cebeci, T. and Smith, A. M. O., "A Finite-Difference Method for Calculating Compressible Laminar and Turbulent Boundary Layers," Journal of Basic Engineering, Sept. 1970, pp. 523-535.

${ }^{14}$ Reuther, J., Thompson, R., Pulsonetti, M., and Campbell, C., "Computational Aerothermodynamic Analysis for the STS-107 Accident Investigation," AIAA Paper 2004-1384, Jan. 2004.

${ }^{15}$ External Aerothermal Analysis Team, "Smooth Outer Mold Line Aerothermal Solution Database for Orbiter Windside Acreage Environments During Nominal Entry Conditions," Engineering Note EG-SS-06-1, NASA Johnson Space Center, Houston, Texas, April 2005, Presented to Orbiter Configuration Control Board.

${ }^{16}$ Gnoffo, P. A. and Weilmuenster, K. J., "Multiblock Analysis for Shuttle Orbiter Re-Entry Heating from Mach 24 to Mach 12," AIAA Paper 93-2813, July 1993.

${ }^{17}$ Kleb, W. L. and Weilmuenster, K. J., "Characteristics of the Shuttle Orbiter Leeside Flow During a Re-Entry Condition," Journal of Spacecraft and Rockets, Vol. 31, No. 1, Jan. 1994, pp. 8-16.

${ }^{18}$ Weilmuenster, K. J. and Gnoffo, P. A., "Solution Strategy for Three-Dimensional Configurations at Hypersonic Speeds," Journal of Spacecraft and Rockets, Vol. 30, No. 4, July-August 1993, pp. 385-394.

${ }^{19}$ Wood, W. A., Alter, S. J., Palmer, G. E., and Saunders, D. A., "Allowable Trajectory Variations for Space Shuttle Orbiter Entry-Aeroheating CFD," AIAA Paper 2008-6559, Aug. 2008.

${ }^{20}$ Wood, W. A. and Alter, S. J., "Allowable Trajectory Variations for Space Shuttle Orbiter Entry-Aeroheating CFD," NASA/TM 2008-215312, June 2008.

${ }^{21}$ Tang, C. Y., Trumble, K. A., Campbell, C. H., Lessard, V. R., and Wood, W. A., "Numerical Simulations of the Boundary Layer Transition Flight Experiment," AIAA Paper 2010-453, Jan. 2010.

${ }^{22}$ Luke, E. A., "Loci: A Deductive Framework for Graph-Based Algorithms," Third International Symposium on Computing in Object-Oriented Parallel Environments (ISCOPE), edited by S. Matsuoka, R. Oldehoeft, and M. Tholburn, Springer-Verlag, Dec. 1999, pp. 142-153.

${ }^{23}$ Luke, E. A., Tong, X.-L., Wu, J., Tang, L., and Cinnella, P., "A Chemically Reacting Flow Solver for Generalized Grids," Aiaa paper, 2003, unpublished.

${ }^{24}$ Gnoffo, P. A. and White, J. A., "Computational Aerothermodynamic Simulation Issues on Unstructured Grids," AIAA Paper 2004-2371, June 2004.

${ }^{25}$ Gnoffo, P. A., "Simulation of Stagnation Region Heating in Hypersonic Flow on Tetrahedral Grids," AIAA Paper 20073960, June 2007.

${ }^{26}$ Gnoffo, P. A., "Multi-Dimensional, Inviscid Flux Reconstruction for Simulation of Hypersonic Heating on Tetrahedral Grids," AIAA Paper 2009-599, Jan. 2009.

${ }^{27}$ Cleveland, W. S., The Elements of Graphing Data, AT\&T Bell Laboratories, Murray Hill, New Jersey, 1994. 
${ }^{28}$ Spisz, T. S., Taylor, J. C., Gibson, D. M., Horvath, T. J., Zalameda, J. N., Tomek, D. M., Tietjen, A. B., Tack, S., and Bush, B., "Processing Near-Infrared Imagery of Hypersonic Space Shuttle Reentries," SPIE Paper 7661-17, April 2010, Thermosense XXXII Conference at the SPIE Symposium on Defense, Security, and Sensing. 